\title{
The Role of Information and Communication Technology (Ict) in Providing Job Opportunities for Youth in the Developing world
}

\author{
${ }^{1}$ mustapha Mohammed, ${ }^{2}$ Haroun G.Haroun ${ }^{3}$ Abdullahi Muhd Sadiq \\ ${ }^{I}$ Senior lecturer NCE, B.ED (Tech) M.sc (Ed) curriculum Department \\ ${ }^{2}$ Lecturer I NCE, B.ED (Tech) M.(Ed) Technical Education Department \\ ${ }^{3}$ Lecturer II NCE, B.ED (Tech) M.(Ed) Primary Education Studies Department College of Education P M B 44, \\ Azare. Bauchi State, Nigeria
}

\begin{abstract}
Information and communication technology (ICT) plays an important role in our everyday life such that it becomes indispensable in the contemporary world. The use of information and communication technology (ICT) has become integral part of our life in such a way that it is inevitable in every aspect of human Endeavour ranging from educational needs, social needs, commercial needs and above all security needs. As part of human capacity building many ICT centers employ youth to manned the centers sometimes twenty four hours daily serving customers in the developing world. The ICT centers in the developing world is now becoming center of attraction as youth engage themselves to seek employment, to chart with friends as well as to propagate social and political views among others..In addition ICT provide the youth with technical knowhow of architectural design in building thereby earning a lot of money from their clients. It also provides job opportunities for the youth where maintenance and repairs are being carried out by the youth. This paper focuses on the major role being played by ICT in the developing world and its contribution to human capacity building and job creation.

Keywords: Information, Communication, Technology, Job Opportunities and Development.
\end{abstract}

\section{Introduction}

The concept of information and communication technology

Information and communication technology (ICT) have profound influence in the contemporary world such that it has taken every sphere of life today. The advent of information and communication technology has made the world a global village where all activities concerning human and material resources are utilized for optimum result.ICT has made every aspect of life easier such that patients living in some part of the world could be diagnosed in another part of the world in a couple of minutes in the same vein commodities manufactured in one part of the world could be sold in another part of the world in few second as maintained by Adebayo and Akinola (2008) that the presence of ICT make the match of globalization an indisputable reality. Indeed, the fast growing developing economies such as China, Singapore and India depend largely on ICT as their major track for their development in all ramifications.The fast growing development of ICT has reached every part of the world including African countries. In his view Oremadu (2003) stated that the advent of ICT and Ecommerce have bound the economies of the world together. In view of the above foregoing significance of the ICT it was generally define by Tinio (2015) as a "diverse set of technological tools and resources used to communicate, and to create, disseminate, store, and manage information." "ICT implies the technology which consists of electronic devices and associated human interactive materials that enable the user to employ them for a wide range of teaching - learning processes in addition to personal use." These technologies include computers, the Internet, broadcasting technologies (radio and television), and telephony. "ICT is that technology which uses the information to meet human need or purposes including processing and exchanging. The system could also be seen as "The acquisition, recording, and processing of data which is finally retrieved as information via electronic signals for usage. ICT therefore refers to the convergence of audio-visual and telephone networks with computer networks, and the technology encompasses a wide range of activities, ranging from office data processing to remote control and monitoring of manufacturing robots. It also covers the cabling infrastructure e.g. fiber optic cables, which carry voice, data and video communications. A major offshoot of the convergence of information and communication technology is the emergence of the internet, which is a content distribution network comprising of a global system of interconnected computer networks through which data is interchanged. The technology consists of millions of private and public academic, business and government networks of both local and global scope which facilitates the dissemination and exchange of information, and makes diverse other forms of non-physical interaction the new reality.

\section{Human capacity building in ICT and job creation in the developing world}

The rapid development of information and communication technology (ICT) in the developing world has become an avenue of providing job opportunities for youth in many counties of the world.According to the 
latest ITU report, Digital Opportunities: Innovative Solutions for Youth Employment (2014) maintained that High youth unemployment not only hampers economic growth but for youth it can be a debilitating experience that affect $s$ their ability to lead productive and rewarding lives. The report further maintained that "To promote youth unemployment it is essential that youth in their countries obtain digital skills, including how to become ICT creators". Moreover, the emergence of social network such as face book, whatsapp, you tube, and twitter has greatly improve the use of ICT in the world .A number of public and private ICT centre's have been running for almost twenty four hours daily in order to serve people with different needs of life. The trend of development in ICT has immensely contributed to providing job opportunities for young men and women who are rooming the streets due to lack of employment in the developing World. It is undoubtedly true that ICT is making significant role in facilitating employment opportunities among youth by manning the centre's as well as performing creativity work such as design of buildings, design of arts work as well as maintenance activities of ICT equipments among others. According to peter Jack (2014) the ICT sector in Nigeria is currently boosting the federal government effort in job creation on an average of about 12 million jobs from 2012 to date which is a significant improvement against the 2.5 million jobs the sector created" between" 2002 - 2012. In line with its investment policy the World Bank express its readiness in providing 2 million dollar investment on facilities to promote growth and employment projects on ICT in Nigeria in the year 2014.In his view Christine zhen- Wei Qiang in(2009) stated that "The mobile platform is emerging as the single most powerful way to extend economic opportunities and key services to millions of people". He further maintained that, investment in telecom services in African region between the years 2000-2007 reached \$20 billion and number of mobile subscribers increased from 2 million in 2000 to over 150 million in 2007.

The universality of ICT has made it an indispensable media for transacting every aspect of human and material resources in the world. This trend of development has provided significant changes in the life of thousandth of youth in the developing world. The trend of development is manifested in the provision of jobs opportunity for self reliance across the globe. For instance, in Nigeria many private organizations have been training young men and women in ICT management in order to be self reliant. Also, governmental organizations such as Subsidy reinvestment programme (SURE-P), National Directorate of Employment(NDE) as well as voluntary agencies are training young people in ICT capabilities. Similarly, Peterson (2012) reported that due to shortage of manpower in ICT, Microsoft South African innovation centre and the International youth foundation promote the students to business enablement programme that aim to place 10,000 graduates in jobs by 2010 . Also, IBM is setting an innovation centre in Johannesburg to help company develop ICT skills and workers meet business challenges. The centre will give access to 38 innovation centres and $60 \mathrm{R} \& \mathrm{D}$ laboratories that IBM has worldwide. MTN is investing in skills development to deal with South Africa's human resources shortage. CISCO is also investing in skills development with the Global Talent Acceleration Program in South Africa. The African Development Bank is investing in information and technology skills at two regional Centers' of Excellence in ICT in Tunisia and Rwanda and in a High Tech Centre in ICT in Mali. These centre's train senior level managers, entrepreneurs, government and private sector employees, and university students pursuing advanced ICT studies. The International Telecommunication Union (ITU) is promoting a scholarship for ICT studies, a Youth Education Scheme (YES), and an internship to develop ICT professional skills, (YIS). Applications for YES can be 12 times higher than that for scholarships. Only Alcatel-Lucent and Thales Communications are participating on YIS by offering training, but taking into account the large number of ICT companies in Africa, more should be involved. The ITU is also promoting a project aiming to raise ICT awareness in indigenous communities. The UN Conference on Trade and Development (UNCTAD) is providing custom training for engineers and technicians from least developed African countries under its Connect Africa project. Lesotho is the first pilot project and gets 220 computers and open source software. UNCTAD is also working on courses that concentrate on biotechnology and ICTs. Nine courses were held between 2006 and 2008 in China, Egypt, India, South Africa, Tanzania and Tunisia. There are three times more applications than there are places. According to the World Bank report on World economic forum (2010), the ICT is becoming the largest distribution flat form of providing public and private services to millions of people in rural and poor areas market information, financial services, education and health services that had largely been unavailable in those areas in the past due to lack of connectivity of any kind. The report further stated that out of 26 sectors from 56 developing countries indicate that businesses that use ICT(phone pc and e mail) more intensively are more productive, grow faster invest more and are more profitable The study include small and medium enterprise globally. A study conducted by World Bank in September 2013, revealed that there are three global drivers responsible for the increase in ICT related jobs worldwide:

a. Greater connectivity- more than 120 countries now have 80 percent market penetration of mobile telephones

b. Digitization of more aspect work- today telecommunicating and outsourcing have become standard business practices globally 
c. More globalized skills-India and the Philippines have become major out sourcing hubs thank to their English language skills, and other countries are targeting the sector for future growth.

In terms of connectivity, the World Bank report further stated that ICT connect about 12 million people worldwide find work by connecting them with employers globally. Companies such as Babajob in India, Duma and M- Kazi in Kenya, and souktel in the Middle East and North Africa are example of job search services using internet- base and mobile tools. Such services empower workers by making labour markets more transparent and inclusive. In another development USAID in Serbia reported that from February to November, 2014 ICT academy equipped unemployed youth with the knowledge and skills in demand by the IT industry. The world economic forum (2009) reports on ICT stated that one of the most opportunities for positive socio economic change lies in the scaling of mobile Health and mobile financial services (MFS). In a similar development the ICT sector in New Zealand showed that there are around 2300 businesses in the sector employing about 46,000 people. The ICT Market in New Zealand appears buoyant as one consultant's survey of 500 employers in private and public sectors showed 75\% plan to hire new staff in 2013 compared with $70 \%$ in January, 2012.Also, the institute of IT professionals in New Zealand noted that ICT job adverts were 30\% up in 2012 compared with two years earlier. A similar development has been the ICT4D programmed which is a programmed designed by the world Bank aimed at bridging the digital divide and aid economic development by fostering equitable access to modern communication technologies .It is a powerful tool for economic and social development (ICTD, 2012). According to Ademiluyi (2014) ICT has offered the developing World with employment opportunities for youths inform of outsourcing, online entrepreneurial opportunities and so on; big corporations abroad prefer outsourcing services to films in the developing world as it is economical than hiring employees elsewhere.

\section{Ict And Education In The Developing World}

The importance of ICT in education in the developing world and the extent to which ICT provide job opportunities in educational sector is one of the tremendous effort made by governments and organizations such as the World Bank in their contributions towards bridging the Digital divide between the developed and developing countries of the world. According to the World Bank report in (2009) it expressed readiness to kickstart a $\$ 2 \mathrm{~m}$ investment on facilities to promote growth and employment in Nigeria.

The use and integration of ICT in building inclusive knowledge societies for all and for overall socioeconomic development is increasingly on the agenda of almost all developing countries of Sub-Saharan Africa. ICT are seen as an important catalyst and accelerator for development, having the ability to attract investment, create job opportunities, promote knowledge building and sharing, facilitate innovation and contribute to good governance and more efficient and transparent provision of public services. ICT facilitate inclusiveness by enabling citizens anywhere to access information and knowledge. ICT together with education empower citizens to be aware of their rights and to participate actively in shaping public policy, governance and development. The International Institute for communication Development (IICD) report in 1998 stated that, IICD develops teacher's abilities to integrate pedagogical and content knowledge in the classroom, helping alleviate common challenges like crowded classroom, resource shortages and outdated pedagogical methods.

The diverse usage of ICT has made it indispensable for the smooth running of education in the developing world in order to achieve excellence in education. The following are some of the uses of ICT in education:

- To broadcast material, online facility or CD-ROM can be used as sources of information in different subjects;

- To facilitate communication for pupils with special needs;

- To use electronic toys to develop spatial awareness and psycho-motor control;

- To use the online resource like, email, Chat, discussion forum to support collaborative writing and sharing of information.

- To facilitate video-conferencing or other form of Tele conferencing to involve wide range of students from distant Geographic areas.

- For Blended learning by combining conventional classroom learning with E-learning learning systems

- To process administrative and assessment data.

- To exchange and share ideas -among teachers for the professional growth.

- To carry out internet-based research to enhance, educational process.

\section{Advantages Of The Use Of Ict In Education:}

The advantages of ICT in education are numerous it encompasses all those gadgets that deal with the processing of information for better and effective communication. In education, communication process takes place between teachers, students, management and administrative personnel which requires plenty of data to be stored for retrieval as and when required, to be disseminated or transmitted in the desired format. The hardware 
and software like printed materials ROM and RAM, Television, Radio, Computers and related software are used in the educational process. However ICT today is mostly focused on the use of Computer technology for processing the data. In this context, advantages of ICT in education can be listed down as follows:

- Quick access to information: Information can be accessed in seconds by connecting to the internet and surfing through Web pages.

- Easy availability of updated data: Sitting at home or at any comfortable place the desired information can be accessed easily. This helps the students to learn the updated content. Teachers too can keep themselves abreast of the latest teaching learning strategies and related technologies.

- Connecting Geographically dispersed regions: With the advancement of ICT, education does not remain restricted within four walls of the educational institutions. Students from different parts of the world can learn together by using online, offline resources. This would result in the enriching learning experience. Such collaborative learning can result in developing...

- Divergent thinking ability in students,

- Global perspectives

- Respect for varied nature of human life and acculturation.

- Facilitation of learning.

ICT has contributed in shifting the focus on learning than teaching. ICT helps students to explore knowledge to learn the content through self study. Teacher can help the students by ensuring the right direction towards effective learning. Situational learning, Programmed learning, many Online learning courses are some of the example of self learning strategies that are being utilized with the help of ICT.

- Catering to the Individual differences: ICT can contribute in catering to individual needs of the students as per their capabilities and interest. Crowded class rooms have always been a challenge for the teacher to consider the needs of every student in the class.

- Wider range of communication media: With the advent of ICT, different means of communication are being introduced in the teaching learning

- Process. Offline learning, on line learning, blended learning is some of the resources that can be used in educational institutions. Collaborative learning, individualized learning strategies can enhance the quality of group as well as individual learning.

- Wider learning opportunities for pupils Application of latest ICT in education has provided many options to the learners to opt for the course of their choices. Many Online courses are available for them to select any as per their aptitude and interest. Students can evaluate their own progress through different quizzes, ready to use online tests. This can ensure fulfillment of the employment required in the job market thus minimizing the problem of unemployment. It can also provide more efficient and effective citizens to the society as per the changing needs.

\section{Ict And Commercial Needs In The Developing World}

The tremendous contributions made by ICTs have brought about significant changes in business practices with respect to banking transactions and, to some extent, the buying and selling of goods and services, through the possibilities of the medium to promote trade and commerce through wider access to prospective customers from anywhere on the globe for products and services. ICTs have thus transformed the business world, including the banking, trading and entertainment sectors, making the sectors more efficient and less limited by the barriers of time, distance and costs. ICTs also have the potential to contribute to poverty alleviation through websites promoting local products in international markets, and facilitating access to market information for competitive prices for locally produced crafts, clothing and farm produce. The technology further offers an opportunity for the exploitation of foreign markets for cultural products, a market which continues to expand in line with increases in the African Diaspora eager for means to access local food, clothes, music, films and other aspects of their cultural identity and heritage. In their own view on ICT Nwabueze and Ozioko (2011) stated that ICT is an essential part of national infrastructure and factor greatly in both public and private sectors business enterprises, it creates business opportunities especially for companies located far from urban centre's and improve links among firms, supplies and clients.

On its part, in the banking sector, the replacement of the age-old ledger system with computers linked to internet facilities has brought about a revolution in the sector. Online/e-banking allows customers to carry out a wide variety of banking and other financial activities online, through a website operated by the bank. A major benefit of internet banking is the ease and convenience of managing one's finances from a place and time of one's choosing. Thus, financial transactions including checking of account balance, monitoring transactions, payment of utility bills, transfer of funds and monitoring, confirmation and stoppage of cheques can be conveniently carried out from any location. A related development is the use of electronic devices such as magnetically encoded plastic cards that permit customers to make cash withdrawals and pay for transactions without visiting banking halls, through ATMs (Automated Teller Machines), POS (Point of Sale) and other 
online channels. The possibilities provided by e-banking, which reduces the need to carry cash on personal and business trips, while also affording ready 24-hour access and convenience for users represents one of the most obvious and potent impacts of ICT in the developing world.

\section{Ict And Cyber Security Challenges In The Developing World}

ICT security challenges are more prevalent in the developed world but the trend has now gradually descended to the developing world. North Korea recently launched cyber security attacked on Sony web sit in April,2014 through her citizen called"Geoltot" Hortz a 21 year old hacker who uncovered (and subsequently shared online) the play station 3s. As a pay back the anonymous an online community launched a series of DDoS (Distributed denial of service) and lock low orbit lon cannon) attacks against the company the two attacks went under the names \#Op Sony and \# Sony Recon. The attack came as a result of some vulnerability of the cyber protection systems of Sony and was able to breach into its data servers, stealing the personal data of more than 77 million of user's worldwide (Global cyber, 2014). These security challenges should adequately be address through intensive research in cyber security handling and monitoring to guard against intercepting Security information all over the world as maintained by president Barrack Obama during world conference on cyber security attack among nations in the World in mid February, 2015.

The problem of cybercrime is a global one whose extent, magnitude and impact reverberate throughout various walks of life, leaving hitherto unimaginable damage in its wake. Therefore it is imperative for government and private organizations to guard against any possible attack of cyber crime on their web site no matter their complexities in all parts of the world.

\section{Conclusion}

The role of information and communication technology in providing job opportunities in the developing World could not be overemphasized as millionth of youth were given job opportunities by both public and private institutions all over the world in ICT capabilities. These opportunities range from educational, commercial, as well as social and security needs in the developing world. The rapid development of ICT has turned the world in to global village as ICT is universally used all over the world in all ramifications.

\section{Recommendations}

$>$ Developing nations should as a matter of urgency provide all necessary facilities for the training of youth in ICT management so as to provide job opportunities for the teaming unemployed youth in their countries.

$>$ Since the use of ICT has become indispensable in all sectors of human Endeavour, therefore greater emphasis should given to provision of ICT facilities in all nook and corners in the developing countries for schools and public consumption so as to bridge the digital divide between developed and developing nations.

$>$ The developing nations are far left behind in terms of provision of ICT facilities for their people, therefore, an intensive commitment in funding all requirements for the provision of ICT facilities should be provided by the governments.

$>$ Developing nations should greatly imbibe maintenance culture in ICT equipments such as the developed nations so that thousands of unemployed youth will gain employment in ICT maintenance.

$>$ Developing nations should intensify effort in the provision of sufficient electricity power supply which is a catalyst for the development of every country in the World and an indispensable by- product of ICT operation.

[1]. Adebayo, G. A. \& Akinola, D.(2008).Globalizing surveillance: The role of mass media in National development . Knowledge review.vol (16)(3) pp104-111.

[2]. Ademiluyi, Adewale.(2014).Creating Employment and Empowerment using ICT for the youths in Nigeria. Retrieved on 24/03/2015 from http//Google//www.legalwealthcollege.com/creating-emp....

[3]. Christine Zhen-Wei Qiang.(2009).Information communications Technology for Development. Retrieved on 20/03/2015 from Http//Google//.www live World Bank.org/information-comm........

[4]. Compuworld web site (2009).Nigeria's ICT sector Growth, gains and challenges. Retrievedon 24/02/2015fromhttp// Google//www. compuworld.com.ng/blog....read.asp.....

[5]. Global cyber (2014).Data breach and electronic crime: The Sony's case.

[6]. Retrieved on 02/02/2015 http:// Google //www.gc sec. org >Home > Blog.

[7]. www.compuworld.com.ng/blog...read.asp...

[8]. IT \& Tech in New Zealand (2015) Immigration \& work info. Retrieved on 16/02/2015.Http:// Google//www.newzealandnow. govt.nz/work/-in-n..

[9]. IICD Report (1998) ICTs in developing countries; Booklet one1-The importance for sustainable development. Retrieved on 20/02/2015 from http//Google//www.iicd.org/articles/IICD news.import9

[10]. ICT4D Report (2012).Information and communication technologies for development. Retrieved on 18 /03/ 2015.<http//Google//www.en Wikipedia. Org/wiki/information....... 
[11]. ITU BLOG. (2014). Innovative ICT solutions for youth unemployment. Retrievedfromhttp// Google//www.itu4u. wordpress. com/2014/05/15/inno....

[12]. Nwabuzie, A.U. \& Ozioko, R.E.(2011).Information and communication Technology for sustainable Development in Nigeria Retrieved on 23/03/2015 from http//Google//www.webpeges. Udaho.edu/ mbolin/nwa.....

[13]. Oremadu, S. O.(2003).The challenges and impacts of E- commerce on Nigerian commercial Banks .An empirical evidence .International journal of economic and development issues. Vol. (3)(1)pp 115-126.

[14]. Tinio, V. L. (2015). What are ICTs and what types of ICTs are commonly used in education? Retrieved on 24/02/2015 from http//Google// www techopedia.....

[15]. USAID (2014) sustainable local development project creates employment opportunities through ICT cluster academy. Retrieved on 15/02/2015 http:// Google//www. Unsaid gov.>Home>News\& information>Events.

[16]. World Bank report (September, 2013). ICTs are creating new jobs and making labour markets more innovative, inclusive and global. Retrieved on 15/02/2015.Http//Google//www .World Bank org /en/ news/press released

[17]. World economic forum (2009).ICT for growth. Retrieved on 20/02/2015 from http: //Google// .www we forum. Org / issues/ ictgrowth.

[18]. World Bank report (2010).Information communications Technology for development. Retrieved on 03/02/2015 from http//Google//.www.live world bank.org/information.comm....... 